\title{
Evolución de los informativos en la radio española. Diarios "de autor" y opinión de los oyentes
}

\section{The evolution of news on Spanish radio. "Authored" news reports and listener opinion}

\author{
Palma Peña Jiménez. Universidad Rey Juan Carlos
}

Recibido: 1-II-2011 - Aceptado: 6-IX-2011

Resumen:

El propósito de este artículo es analizar la incorporación progresiva de elementos de análisis y opinión a los informativos de radio, un género reservado a la transmisión exclusiva de noticias. El estudio realizado revela el uso extendido de entradillas interpretativas por parte de los presentadores, así como la inclusión de secciones fijas de análisis político. Se constata además la participación creciente de oyentes e internautas que, gracias al correo electrónico y las redes sociales, ven reflejadas sus opiniones en el curso del informativo. Asistimos así a un proceso de revisión del género que otorga al informativo radiofónico una condición híbrida antes desconocida y cuyo último hito es la incorporación a la antena, en tiempo real, de la opinión de los oyentes.

Palabras clave:

Información, Internet, opinión, participación, radio, redes sociales

Abstract:

The purpose of this paper is to analyse the gradual incorporation of analysis and opinion into radio news reporting, an area previously dedicated exclusively to transmitting news. A study of news programmes on Spanish radio reveals the widespread use of interpretive introductions by presenters and the incorporation of sections dedicated to political analysis. The report also confirms growing influence amongst listener and internet user, who via email and social networks are able to ensure their opinions are reflected in news bulletins. We are therefore seeing a process of great change in radio news as it has a previously unheard of hybrid status bestowed upon it, the epitome of which is the real-time incorporation of listener opinion into news programmes.

Key words:

Information, Internet, opinion, participation, radio, social networks 


\section{Introducción}

Desde que hace ochenta años se iniciara en España la emisión regular de un “diario hablado”, la información radiofónica ha experimentado una notable evolución. Este estudio analiza la incorporación paulatina de elementos de opinión a los servicios de noticias, en la mayoría de los cuales se escucha hoy, tanto el juicio de los presentadores sobre los hechos y acontecimientos de la actualidad, como el parecer de los colaboradores del programa; y, en algún caso puntual, pero en clara progresión, el sentir de oyentes y usuarios de la Red.

El artículo fija su atención en aquellos espacios informativos que hacen uso de las distintas aplicaciones disponibles en la Red para incorporar, en el curso de la emisión, las comunicaciones de oyentes e internautas. En el ánimo de este trabajo está verificar los cambios experimentados en la edición de informativos de radio tras la emergencia de estas nuevas herramientas, y comprobar en qué medida estos flamantes instrumentos alteran los contenidos del programa.

\section{Objeto de estudio: los diarios hablados o servicios principales}

Constituyen nuestro objeto de estudio los "diarios hablados" de las grandes cadenas de radio, entendiendo por tales, aquellos espacios de información general y edición regular diaria que, junto con los boletines de noticias, caracterizan y vertebran las emisiones "generalistas". Se trata de informativos de treinta o sesenta minutos de duración, programados en franjas horarias de mañana (desde las 6 horas), mediodía (14 horas), tarde (20 horas) y noche (a partir de las 22 horas), de acuerdo con los hábitos de consumo y las costumbres sociales (Tapia, 1994: 40). La posible coincidencia con el prime time televisivo de noticias responderá a la estrategia de cada emisora, que optará por situar la información en horario de emisión igual o diferente al de los telediarios, haciendo así compatibles o irreconciliables, respectivamente, ambos consumos, en el primero de los casos, buscando la complementariedad entre ambos servicios, y en el segundo, aspirando a un target alternativo.

El Manual de estilo de Radio Nacional de España se refiere a los diarios hablados como aquellos espacios en que "entrarán ampliadas" (1980: 58) las noticias ya avanzadas en los boletines horarios. La información se ofrece aquí con más detalle y complementada con testimonios de protagonistas, testigos, expertos y diferentes actores políticos, entre otros. Destacan también las crónicas de los corresponsales en el exterior y de los redactores de las emisoras locales, así como la emisión de sumarios que se intercalan en el transcurso del informativo (Muñoz y Gil, 1994: 110) a fin de recordar a los oyentes las claves de la actualidad y facilitar, al mismo tiempo, la incorporación de nuevos seguidores. Todos estos elementos se suceden, uno tras otro, siguiendo los "pasos" del presentador, cuya voz constituye el hilo conductor del informativo, contribuyen a la comprensión y al ritmo del diario.

Uno de los principios básicos que inspiran y caracterizan el diario hablado es su disposición a incluir cuantas contingencias puedan sobrevenir en el curso del programa (Ortiz y Volpini, 1995: 149). Por definición, el noticiero estará siempre 
sujeto a eventualidades que alterarán las previsiones del editor. Estas circunstancias pueden modificar la jerarquía informativa inicialmente planteada, el orden y duración de los elementos, así como el enfoque global o parcial del informativo. Por esta razón, lejos de tratarse de un guión stricto sensu elaborado para una lectura literal, nos encontramos ante una suerte de índice, pauta o escaleta, cuya función es vertebrar y organizar el informativo, pero nunca constreñir el espíritu "abierto" que debe caracterizar a un producto de estas características, atento por definición al "imperativo" de la actualidad (Ortiz y Volpini, 1995: 152).

Desde un punto de vista estructural, los diarios hablados comienzan con el saludo del editor seguido de una presentación o entrada general que puede emplearse en describir, contar, resumir, preguntar, parodiar o generar el suspense, apuntando y manteniendo una determinada incógnita (Ulibarri, 1994). A continuación se lleva a cabo -generalmente, a dos voces y sobre un fondo musical- una lectura de los titulares de las noticias más relevantes de la jornada, parte de las cuales se completarán ulteriormente en el orden y extensión que estime oportuno el responsable del programa. Estos informativos "principales" se caracterizan por ofrecer las noticias separadas por ráfagas musicales (en ocasiones, también, por cuñas publicitarias o promociones de la emisora) que, al mismo tiempo, aparecen conectadas entre sí de forma más o menos creativa, dependiendo del estilo de cada editor, así como de las dotes escénicas con que cuente el presentador del programa. En la práctica, ambas tareas recaen sobre la misma persona.

En cuanto al aspecto periodístico, partiendo de los valores-noticia, los informativos de radio aplican en su proceso de producción los criterios conocidos de actualidad, inmediatez, espectacularidad, magnitud, proximidad, curiosidad, comprensión, periodicidad, interés humano, carácter de la fuente informativa, exclusividad, conflicto o desarrollo noticioso, entre otros (Martini y Luchessi, 2004: 117). De forma resumida, la praxis enseña que las informaciones se convierten en noticias cuando adquieren la suficiente relevancia y aportan alguna novedad (Martini, 2000: 75).

Desde otra óptica, puede afirmarse que en los informativos se atienden y conjugan, con mayor o menor acierto, hasta tres elementos: de un lado, el interés general del oyente (y de la sociedad, por extensión); de otro, los objetivos del medio, ya sean éstos de naturaleza ideológica, comercial o corporativa; y, por último, la voluntad de determinados sectores sociales, políticos o económicos de difundir “aquellos hechos que sirven a sus objetivos” (Oriol, 2008: 204-205).

\subsection{La selección de noticias en los informativos radiofónicos}

A diferencia de la prensa tradicional, la radio generalista presenta hasta cuatro ediciones informativas a lo largo del día. El proceso de producción se caracteriza así por una continua labor de renovación que compete a los editores correspondientes de cada uno de los diarios hablados, bajo la supervisión de los órganos de dirección, en particular, de la jefatura de informativos. A ellos corresponde decidir la cobertura de cada noticia, así como la orientación deseada, el tiempo de desarrollo, su ubicación en el informativo -en la cadena causal-y los testimonios sonoros que, en cada caso, correspon- 
dan. El cometido de estos periodistas-selectores (gatekeepers en terminología anglosajona) es, en definitiva, establecer la agenda setting y orientar, a tales efectos, el trabajo de la redacción.

No obstante, junto a los criterios de noticiabilidad apuntados, los editores aplican otros principios, que van desde la "necesidad de [...] completar el ciclo informativo diario" hasta la toma en consideración de "su contexto profesional-organizativo" (Armentia y Caminos, 2009: 208). Por esta razón, aquellas noticias que obstruyan o dificulten el proceso productivo serán previsiblemente apartadas de la escaleta final, por más que pudieran resultar, en origen, relevantes. Sirvan de ejemplo aquellas noticias que requerirían una extensa y dificultosa explicación -como es el caso frecuente de la información económicao aquellas otras que no pueden acompañarse de testimonio sonoro alguno, circunstancia que puede desaconsejar su inclusión en el informativo, en espera de una más adecuada presentación.

Cabe afirmar, en consecuencia, que la selección de noticias no obedece exclusivamente al interés de los oyentes y tampoco a la aplicación de criterios profesionales a partir de los valores-noticia, sino que, en el mencionado proceso concurren otros factores: unos, puramente funcionales, como la necesidad de elaborar un informativo diario, a una hora determinada, con una duración prefijada e inamovible y con los exclusivos elementos de que se dispone; otros, relacionados con su condición de miembros de una empresa, como el sentimiento de pertenencia -siempre determinante- que Armentia y Caminos (2009: 208) concretan, además de en las rutinas productivas, "en la aceptación de su grupo profesional y de sus superiores".

Tampoco debe olvidarse aquí la tendencia de los individuos a no hacer pública su opinión en el seno de un grupo en el que se sienten en minoría, por miedo a las consecuencias que puedan derivarse de sus manifestaciones (Anderson, 1996: 214). Teniendo presente la formulación de Noelle-Neumann (1974) sobre la "espiral del silencio", resulta fácil deducir que su condición de dependencia llevará a los periodistas-selectores a no entrar en excesivas contradicciones con la filosofía de la empresa, pero tampoco con los compañeros de redacción o con el colectivo general de periodistas, en tanto "miembros" del grupo (Miller, 2005: 277). Entre las numerosas razones que llevarán al selector a acompasar su criterio personal con el del grupo, Armentia y Caminos (2009: 208) señalan "el respeto a la autoridad y las sanciones que pueda aplicar, los sentimientos de obligación y estima hacia los superiores, las aspiraciones profesionales, la ausencia de fidelidades de grupo contrapuestas a los órganos de decisión, la naturaleza del trabajo cuando forma parte de un empleo profesionalmente satisfactorio, etc.". Sumamos a esta atinada lista las necesidades sociales de "afiliación" que presenta todo individuo (Sallenave, 2002: 59, 63 y 67), así como, en otro orden de cosas, el "corporativismo" que caracteriza a la profesión. Ciertamente, los miembros de una organización o de un colectivo se acoplarán, con toda seguridad, al criterio general del grupo, "aceptando" la tesis de la mayoría, evitando así entrar en conflicto con el pensamiento mayoritario, y en ocasiones único. 


\section{Génesis y evolución del diario hablado}

\subsection{Los primeros informativos: la "radio de tijeras"}

En 1923 se escuchó en la WJZ de New York el primer programa dotado de una estructura periodística. Su responsable, Bill Slocum, se erigió así en pionero de la radiodifusión informativa mundial, inaugurando el primer "diario hablado" de la historia. Se trataba, ciertamente, de un periódico sonoro, algo previsible si tenemos en cuenta tres circunstancias: primero, que la radio era un artilugio recién estrenado y en plena experimentación; segundo, que el nuevo medio no podía inspirarse, a estos efectos, más que en la prensa; y, tercero, que fue un periodista quien la puso en marcha: el redactor jefe del Herald Tribune.

La historia demuestra la tendencia de todo medio de comunicación a conservar, en sus inicios, "las estructuras no funcionales" de otros medios precedentes. No en vano, la prensa necesitó dos siglos para apartarse definitivamente de la literatura y encontrar el estilo propio, conciso y directo que hoy conocemos, alejado, en todo caso, del ornato propio de las composiciones literarias. Con estos antecedentes, el primer informativo de la historia de la radio no podía denominarse de otra forma que "diario hablado", circunstancia que venía a demostrar que lo esencial se mantiene. En estas circunstancias, difícilmente podía Slocum percatarse de la diferencia entre escribir para ser leído y escribir para ser escuchado. Acertadamente, Hill (1987: 113) escribe que el periódico y el pregonero, como la radio y la televisión, comparten el objetivo de difundir la información pero, en absoluto, el método; afirmando, en consecuencia, que "haber dado a los espacios informativos en radio y televisión títulos como "telediario" o "diario hablado" [...] indican una confusión entre el fin y el método para lograrlo". Verdaderamente, Slocum trasladaba a los oyentes lecturas literales del contenido de la prensa. Tal praxis desencadenó un nada despreciable conflicto con los periódicos que, pronto, la CBS intentó neutralizar creando para ello la CNS (Columbia News Service), una agencia de noticias específica para la radio. Se acuñó entonces la expresión "radio de tijeras", manifestación ciertamente irónica en relación con la actividad "subalterna" de los primeros radiofonistas. No obstante lo anterior, aquellos programas de 15 minutos de duración ofrecían un producto netamente informativo.

\section{2. “La palabra", el primer diario hablado español}

En España, tras varios intentos fallidos, el martes 7 de octubre de 1930 se escucha “La palabra”, el primer diario hablado de nuestra historia emitido en cadena por Unión Radio. Después de muchas vicisitudes -entre ellas, el rudo enfrentamiento con las editoras de prensa-, La palabra se emite con periodicidad diaria, a excepción de las mañanas de los lunes y las tardes de los domingos, respetando así el descanso semanal que se aplicaba entonces a la prensa escrita. Podía escucharse también una edición de tarde, a las 19 horas, "después de las campanadas de Gobernación y de las cotizaciones de Bolsa y de mercancías de las principales bolsas extranjeras” (Garitaonandía, 1985: 394-395). 
En un claro intento de suavizar la tensión existente con los periódicos de la época, la revista Ondas, órgano de prensa de la compañía Unión Radio, dedica su número 277, de fecha 4 de octubre de 1930, al nuevo servicio de noticias por radio, afirmando que no comporta competencia alguna con la prensa, ya que "los caminos de ésta y del micrófono son distintos". También adelanta Ondas la duración del programa (veinte minutos) y su estructura, que constaría de una parte netamente informativa y otra de vocación cultural. Y así se anticipaba: "Primeramente, la información oficial, después la política, sin distinción de matices, información de sociedad, de teatro, de deportes, social, comercial, sucesos, etc. Después, información del extranjero" (Blanco Carpintero, 2006: 249).

\subsection{El caso español: la información, interrumpida y condicionada}

La radio evoluciona en España al compás de los acontecimientos históricos del siglo XX. Cabe señalar, desde su nacimiento hasta la actualidad, cinco grandes fases: primera (1924-1931), correspondiente a la génesis del nuevo medio; segunda (1931-1936), coincidente con la II República; tercera (1936-1939), que abarca los años de la Guerra civil; cuarta (1939-1975), desarrollada durante las cuatro décadas de dictadura; y quinta, y actual, inmersa en el marco democrático vigente, en aplicación de la Constitución de 1978.

Las primeras emisiones regulares en España datan de 1924, y se han de atribuir a Radio Madrid (Faus, 2007: 203). Dentro de esta primera fase, asistimos en 1930 al nacimiento de "La Palabra", de Unión Radio, el primer informativo de la radiodifusión española.

El uso de la radio se extiende en tiempos de la II República. Los políticos están persuadidos de la capacidad del nuevo medio para llegar al electorado. Se estrenan en esa época, en Madrid y Barcelona, las retransmisiones de los plenos municipales. La radio compite con la prensa, mermando la venta de periódicos, no en vano, el informativo "La Palabra” llegó a contar diez ediciones diarias.

La tercera fase se circunscribe a los años de la contienda civil, que sirvió para experimentar las virtualidades de la radio como "arma de propaganda" (Garitaonandía, 1988). Destaca en esta época la inauguración en Salamanca, el 19 de enero de 1937, en plena conflagración, de Radio Nacional de España (Orozco, 2009).

La cuarta etapa se corresponde con las cuatro décadas de dictadura. El potencial de la radio resultó tan evidente durante la guerra que, una vez concluida, Franco encomendó a Falange Española y de las JONS la censura previa de la actividad de las emisoras y encargó la información, en exclusiva, a Radio Nacional de España.

Desde ese instante, por Orden de 6 de octubre de 1939, todas las estaciones conectarían con Radio Nacional a las dos y media de la tarde y a las diez de la noche para transmitir, en directo, los informativos de la cadena del Régimen. Durante décadas, los noticieros radiofónicos fueron conocidos por los ciudadanos como "el parte", un vestigio de lo que fueron los 
partes oficiales de guerra durante la contienda civil, que se emitían justo antes del informativo propiamente dicho ${ }^{1}$. La información política quedó así reservada a RNE, limitándose el resto de emisoras a ofrecer a sus oyentes información local que, salvo contados "atrevimientos", se limitaban a la cultura, las agendas y las llamadas informaciones "de servicio público" (farmacia de guardia, cartelera, esquelas, bomberos, policía, etc.).

Siendo información y dictadura términos "antitéticos", durante décadas "la gran ausente es la información” (Faus, 2007: 875). Así lo ponía de manifiesto el "Estudio sobre los medios de comunicación de masas en España” (1964: 687-688), que hacía públicos los tiempos dedicados a la información por las estaciones de Madrid, exceptuada RNE: Radio Madrid, 3,52\% de la programación; La Voz de Madrid, 0,68\%; Radio España de Madrid, 0,42\%; Radio Juventud de España, 0,63\% y Radio Intercontinental, $1,25 \%$.

Una quinta fase se inaugura, tras la muerte de Franco, con la Transición política y la promulgación de la Constitución de 1978. Se inicia en esta etapa un proceso de liberalización que culmina con la derogación de la Orden de 1939. No obstante, las emisoras mantuvieron la conexión obligatoria con los informativos de $R N E$ hasta la entrada en vigor del Decreto de 6 de octubre de 1977. Terminan así casi cuatro décadas (1939-1977) de monopolio informativo de la emisora pública.

\subsection{Separación entre información y opinión}

Desde el origen, la empresa radiofónica ha subrayado la necesaria separación entre géneros informativos y géneros de opinión. Así se registra en los primeros libros de estilo y se deduce de la propia praxis de los noveles noticieros. El número de la revista Ondas (1930) antes mencionada compromete con los oyentes del informativo "La Palabra" una información objetiva, carente de prejuicios: “Todo sin interpretación ni comentario alguno por parte de Unión Radio. En la información, ["La Palabra”] buscará una imparcialidad exquisita para dar el hecho escueto, tal y como haya ocurrido, a ser posible”.

Superados los períodos siguientes de Guerra civil (1936-1939) y de Dictadura (1939-1975), ya en la etapa democrática, la Constitución de 1978 reconoce en su artículo 20 la libertad de expresión y el derecho a la información; y, en ese contexto, por mandato constitucional expreso (artículo 20.3) se promulga por Ley 4/1980, de 10 de enero, el Estatuto de la Radio y la Televisión (vigente hasta el 7 de junio de 2006). De esta norma se deriva el Manual de estilo de Radio Nacional de España (1980) que, de acuerdo con el artículo $4^{\circ}$ del referido Estatuto, establece que su actividad se inspirará en los principios de "objetividad, veracidad e imparcialidad de las informaciones", así como en la "separación de informaciones y opiniones...". El manual insiste en que la noticia "debe llegar al oyente de tal forma que jamás se pueda apreciar el criterio personal del que la ha elaborado" (1980: 56).

A la lectura de los primeros noticiarios de la dictadura precedía el toque de "atención" de un cornetín de órdenes, seguido de una llamada militar "a reunión” del siglo XV. El informativo se despedía con un segundo toque de cornetín y, a continuación, la invocación “Gloriosos caídos por Dios y por España, ipresentes!”, seguida del Himno nacional. 
Con el paso de los años, los noticieros de todas las cadenas evolucionan abriendo la puerta, paulatinamente, a géneros como el reportaje, la encuesta, la entrevista, el informe o las opiniones firmadas, aproximándose a una suerte de "informativo mixto", entendiendo por tal un "noticiario fragmentado, entre cuyas partes se emite publicidad, música, entrevistas extensas o coloquios” (Muñoz y Gil, 1994: 111).

\subsection{El presente: informativos "puros", "diarios de autor" y opiniones de terceros}

En la actualidad, la información radiofónica integra en su escaleta nuevos elementos que invitan, desde la praxis, a una revisión doctrinal de la definición de "diario hablado" (González, 2001: 214 y Ortiz y Marchamalo, 1994: 128). Los actuales noticieros combinan géneros diversos, y en muchos casos se han convertido en diarios "de autor".

Tan sólo las emisoras públicas, sujetas a una normativa específica, observan una obligada separación de información y opinión, de tal modo que sus informativos no incluyen formalmente más opinión que la que puedan verter los protagonistas de la actualidad, testigos, expertos y, en general, los actores públicos². La Ley y los Estatutos de Informativos -en el caso de $R N E$ - impiden a los presentadores de noticias la manifestación de juicios personales 3 . Otro asunto diferente es que el mero desglose de los ámbitos mencionados de la información y la opinión conlleve por sí mismo una garantía absoluta de que los informativos no trasladan la línea editorial de la cadena o el sentir personal del profesional que elabora la información. Servirá tener presente a estos efectos que la mera ausencia en la escaleta del informativo de determinados asuntos de la agenda pública constituye una opinión en sí misma, como también el orden de prioridad establecido para las noticias determina su relevancia.

Los noticieros de las emisoras públicas responden así, en general, al esquema del “informativo puro", modalidad que formalmente no incluye opinión y que, además, proyecta la identidad de la emisora, relegando al presentador a un segundo plano. En el otro extremo se sitúa el diario "de autor", en el que prevalece el estilo del periodista, que traslada a los oyentes una interpretación personal de los acontecimientos, sin ocultación ninguna de su posición.

Por último, y como consecuencia del reciente "matrimonio tecnológico entre la radio e Internet” (Jaramillo, 2003: 190), algunos informativos experimentan con las comunicaciones que los oyentes les trasladan a través del correo electrónico o las redes sociales, incorporando tímidamente a la antena tales misivas (Peña, 2010). Asistimos en este caso a una nueva forma de participación, propia de un nuevo paradigma que obliga a una revisión continuada de la posición del receptor, cuyas opiniones se incorporan en el curso de la emisión gracias a Internet. Ciertamente, "la moderna interfaz de usuario

Véase el art. 9.1 del Estatuto de Información de la Corporación RTVE, de 18 de abril de 2008.

3 El artículo $8^{\circ}$ de la Ley 17/2006, de 5 de junio, de la radio y la televisión de titularidad estatal dispone que "Los profesionales de la información [...] están obligados a cumplir los deberes que comporta el servicio público y, especialmente, distinguirán y separarán la información de la opinión...”. 
es interactiva por definición" (Manovich, 2005: 103) y su consecuencia inmediata es el incremento de la participación. En los orígenes del medio, el destinatario se limitaba a descifrar el mensaje y dar forma a las imágenes recibidas (Hendy, 2000: 145); ahora, gracias a las redes sociales, se expande una práctica de co-creación que permite a los oyentes constituirse en comunidades virtuales activas alrededor de una emisora, un programa o un comunicador (Gallego, 2010: 128). Verdaderamente, la convergencia en Internet convierte a todo usuario en potencial "prosumidor" (Cloutier, 1973) y le otorga otra gran virtualidad, que es formar parte de una comunidad de iguales (Shirky, 2008: 106).

Superadas las limitaciones técnicas, y revisada en la praxis la rígida taxonomía de los géneros periodísticos, las comunicaciones del oyente se incorporan de forma inmediata al informativo. La dicotomía establecida por Jenkins (2004) entre viejos y nuevos consumidores atribuye a estos últimos la condición de activos, y reconoce además el exorbitante potencial de la Red para "reconstruir las jerarquías del conocimiento a través de diferentes formas de participación democrática" (Livingstone, 1999). La acertada predicción de Lin (2001) en referencia al previsible desgaste que los medios clásicos experimentarían por causa de la expansión de Internet, sólo resulta combatible con el maridaje entre la Red y la vieja radio.

Desde un punto de vista funcional (Herrera, 2005: 130-131), esta flamante forma de relación entre comunicadores y oyentes constituye -afirma Gallego (2010: 143)- una manera de "reconectar con la sociedad", y advierte -siguiendo a Lara (2008)de la necesidad de la radio de "crear contextos donde sus audiencias puedan interactuar con el medio y con otros usuarios, donde la gente sienta el espacio como suyo, como un lugar de pertenencia y de referencia personal y comunitaria...". Se trata, en suma, de una nueva forma escuchar, pero también de una revisión estratégica de la radio, obligada a adaptarse a nuevas audiencias, en contextos desconocidos y con novedosas "necesidades comunitarias" (Gallego, 2010: 143).

\section{Método}

El trabajo de campo se ha realizado durante los meses de enero a marzo, ambos inclusive, de 2011. Se inicia con una exploración de la oferta de radio generalista, fijando la atención en los servicios informativos de las cinco cadenas más escuchadas, de acuerdo con los resultados de audiencia que arroja el Estudio General de Medios, EGM, por este orden: SER, Onda Cero, COPE, Radio Nacional y Punto Radio.

El estudio se proyecta sobre aquellos informativos que resultan equiparables desde el punto de vista de su duración y estructura. De esta forma, se analizan los contenidos de los diarios de las dos de la tarde y de las veinte horas. No obstante, por razones de homogeneidad, los resultados cuantitativos se extraen del examen y comparación de los diarios hablados de las 20 horas, franja horaria donde se observan las mayores similitudes en lo que a extensión y configuración se refiere.

De este universo de análisis, se ha seleccionando, de forma aleatoria, una semana de cada mes. Se examinan, por tanto, tres semanas de emisión que, a cinco días por semana (de lunes a viernes), dan como resultado un conjunto de quince in- 
formativos por cada una de las cinco cadenas mencionadas. Componen así la muestra de este estudio un total de 75 diarios hablados (75 horas de emisión), 75 unidades de análisis.

Se observan a continuación las características de cada uno de los informativos registrados, en el ánimo de detectar la presencia de opiniones, ya sean propias o ajenas a la redacción: expertos, protagonistas y oyentes. Una vez reconocidos y catalogados estos elementos, procedemos a encuadrarlos en las tipologías clásicas o, en su caso, en los formatos novedosos antes citados: ya sean diarios de autor o informativos que incorporan la opinión de los oyentes.

\section{Resultados}

El estudio realizado constata la convivencia de tres modelos diversos de información radiofónica que, desde el punto de vista formal, se corresponderían con: el "informativo puro" -entendiendo por tal, aquel que no ofrece opiniones explícitas-; el "diario de autor" -que incluye el juicio expreso del presentador-; y un tercer modelo que llamaremos "híbrido", en que, no ofreciéndose la opinión expresa del conductor del programa, las noticias se complementan con análisis y juicios formulados por terceras personas, ya sean periodistas ajenos a la redacción, expertos u oyentes.

Entre los informativos diarios de las dos de la tarde, el modelo "híbrido" se revela como el más habitual (Tabla I). Es el caso de "Hora 14", noticiero que emite la Cadena SER y que incluye "El Telegrama”, opinión que "firma" el periodista Miguel Ángel Aguilar a las 14:35 horas. Por su parte, "Noticias mediodía”, en Onda Cero, complementa sus informaciones, crónicas e informes con la sección "El bisturí", de Pilar Cernuda. Este informativo incluye "entradillas de autor" por parte de la editora-presentadora, Elena Gijón, y ofrece diariamente el resultado de la encuesta que la página web de la emisora realiza entre sus seguidores en la Red. "La Palestra”, en la cadena COPE, cuenta con el juicio diario del periodista Jenaro Castro, con el título "El vermú". Punto Radio, en esta misma línea, pone en antena "Primera Plana”, que a las 14:40 ofrece "El confidencial”, una sección de opinión a cargo del periodista Fernando Jáuregui. Tan sólo Radio Nacional de España se aparta en "14 Horas" de esta tónica general de incluir opiniones de terceros, dejando a un margen siempre las declaraciones propias de los diversos actores políticos. 
Tabla I. Informativos de las dos de la tarde. Tipología

\begin{tabular}{|l|l|l|l|l|l|}
\hline \multirow{2}{*}{ Emisora } & Horario & \multirow{2}{*}{ Título } & \multirow{2}{*}{ Tipo } & \multicolumn{2}{|c|}{ Secciones de opinión } \\
\cline { 5 - 6 } & & & & Firmas & Oyentes \\
\hline SER & $14: 00-15: 15$ & "Hora 14" & Híbrido & "El Telegrama" & No \\
\hline Onda Cero & $14: 00-15: 05$ & "Noticias mediodía” & De autor & "El bisturí" & No \\
\hline COPE & $14: 00-15: 05$ & "La Palestra" & De autor & "El vermú" & No \\
\hline RNE & $14: 00-15: 00$ & "14 Horas" & Puro & No & No \\
\hline Punto Radio & $14: 00-15: 00$ & "Primera plana" & Híbrido & "El confidencial” & No \\
\hline
\end{tabular}

A las ocho de la tarde, las emisoras generalistas inician un espacio contenedor que se extiende hasta la media noche, con tramos diversos destinados al deporte, la economía y la tertulia. Durante los primeros sesenta minutos, se desarrolla un primer tramo de información general cuya estructura responde -según cada caso- a uno de los tres modelos apuntados (Tabla II). El horario de emisión, no obstante, coincidente con el término de la jornada, invita a planteamientos más reflexivos y pausados. Por esta razón, la franja de tarde-noche resulta más apropiada para esquemas que, superando la mera transmisión de noticias, se adentran en un proceso de interpretación de la actualidad que trasladan y comparten, en última instancia, con los oyentes.

Tabla II. Informativos de las ocho de la tarde. Tipología

\begin{tabular}{|l|l|l|l|l|l|}
\hline \multirow{2}{*}{ Emisora } & Horario & Título & \multirow{2}{*}{ Tipo } & \multicolumn{2}{l|}{ Secciones de opinión } \\
\cline { 5 - 7 } & & & Firmas & Oyentes \\
\hline SER & $20: 00-21: 00$ & "Hora 25" & Híbrido & No & Sí \\
\hline Onda Cero & $20: 00-21: 00$ & "La Brújula" & De autor & "El dardo" & Sí \\
\hline COPE & $20: 00-21: 00$ & "La Linterna" & De autor & No & No \\
\hline RNE & $20: 00-21: 00$ & "24 Horas" & Puro & "El péndulo" & No \\
\hline Punto Radio & $20: 00-21: 00$ & "De costa a costa" & Puro & No & No \\
\hline
\end{tabular}

Y así, la Cadena SER emite “Hora 25”, con Àngels Barceló, programa que se presenta formalmente como un informativo puro, si bien incluye una sección específica con la opinión de los oyentes. 
Radio Nacional de España, por su parte, inicia a las ocho de la tarde el informativo "24 Horas", que dirige Íñigo Alfonso. El presentador reserva para el debate el espacio "El péndulo", donde dos expertos manifiestan su opinión, más o menos encontrada, sobre el tema del día.

La COPE emite a esa hora "La Linterna”, de Juan Pablo Colmenarejo. No incluye opiniones de terceras personas (analistas, expertos u oyentes). Sin embargo, su planteamiento formal es inequívocamente de autor.

Punto Radio emite “De costa a costa”, dirigido y presentado por Pepa Sastre, un diario que no contempla sección alguna de opinión y responde claramente al patrón formal del informativo puro.

Por último, el programa “La Brújula” que, en Onda Cero, dirige y presenta el periodista Carlos Alsina, se revela como paradigma de informativo "de autor", e incluye, además, diversos espacios de análisis. Se inicia a las 20 horas con una salutación breve e identificativa - "Les voy a decir una cosa"- que, a modo de "santo y seña", busca la complicidad del oyente. Tras el saludo, se escucha una plática (exordio) de entre cinco y siete minutos que traslada a los oyentes una interpretación inequívocamente personal de la actualidad de la jornada. Se ofrecen seguidamente los titulares de las noticias más importantes del día para, acto seguido, iniciar el desarrollo de algunas de esas noticias. En este punto se incorpora una selección de las comunicaciones remitidas por el público a través del correo electrónico o de redes sociales. No obstante, tales misivas de los oyentes afloran en cualquier momento durante el curso del programa, a juicio del presentador. Se trata de una diferencia sustancial con otros programas, en los que se reserva una sección específica, a una hora determinada, para ofrecer las comunicaciones más interesantes de los oyentes.

También resulta de interés comprobar cómo el conductor del programa no se limita a una simple lectura de las mejores o más oportunas misivas del oyente, como hace "Hora 25" en la Cadena SER. En el caso de "La Brújula", su conductor contesta al oyente; agradece sus comentarios; se compromete a revisar su posición editorial, reconociendo la existencia de otro punto de vista; pide disculpas, llegado el caso; y lo que es más importante a nuestros efectos, interactúa con el público: dialoga; le agradece su colaboración; manifiesta su solidaridad, su sorpresa, su desconocimiento, su conformidad o su disenso con el comentario expresado; y le invita, en ocasiones, a escribir nuevamente, circunstancia que -de producirse-dará pie a inaugurar nuevamente el circuito dialógico, gracias a la radio y a la Red.

Digamos, por último, que estas comunicaciones electrónicas han procurado a "La Brújula" algunas noticias relevantes que, sobre la marcha o con posterioridad, el equipo de edición ha podido confirmar y completar. Excepcionalmente, los oyentes han facilitado datos desconocidos por la redacción, comportándose como auténticos “informadores espontáneos" (Muñoz y Gil, 1994). Tales revelaciones han llegado a provocar un cambio en el enfoque inicial del equipo de edición del programa.

Cuantificados en términos absolutos y relativos, se ofrecen seguidamente los tiempos que los diarios de tarde de las distintas cadenas de radio dedican a la información, la opinión, los deportes y la publicidad, así como a la promoción de la 
propia cadena (Tabla III). La última línea de la tabla presenta dos tipos de totales: de un lado, los minutos acumulados por la suma de las cinco cadenas a cada uno de los tipos de contenidos, y de otro los porcentajes que representan.

Tabla III. Informativos de las ocho de la tarde. Desglose de tiempos por contenidos

\begin{tabular}{|c|c|c|c|c|c|c|c|c|}
\hline & \multicolumn{2}{|c|}{ Información } & \multicolumn{2}{|c|}{ Opinión } & \multicolumn{2}{|c|}{ Deportes } & \multicolumn{2}{|c|}{ Publicidad \& promos } \\
\hline Emisora & Min & $\%$ & Min & $\%$ & Min & $\%$ & Min & $\%$ \\
\hline SER & 23 & $38 \%$ & 1 & $1,7 \%$ & 30 & $50 \%$ & 6 & $10 \%$ \\
\hline Onda Cero & 26 & $43 \%$ & 11 & $18 \%$ & 13 & $22 \%$ & 10 & $17 \%$ \\
\hline COPE & 14 & $23 \%$ & 10 & $17 \%$ & 31 & $52 \%$ & 5 & $8 \%$ \\
\hline$R N E$ & 47 & $78 \%$ & 10 & $17 \%$ & 2 & $3,3 \%$ & 1 & $1,7 \%$ \\
\hline Punto Radio & 40 & $67 \%$ & 0 & $0 \%$ & 14 & $23 \%$ & 6 & $10 \%$ \\
\hline TOTALES & 150 & $50 \%$ & 32 & $11 \%$ & 90 & $30 \%$ & 28 & $9 \%$ \\
\hline
\end{tabular}

La Fig. 1 permite una rápida visualización del porcentaje que dedican las cadenas estudiadas a cada uno de los cuatro grandes campos de contenido: información, deportes, opinión en sus distintas versiones, y publicidad y promociones de cadena. El gráfico siguiente (Fig. 2) ofrece el contraste entre información y opinión. Se presenta desglosado por emisoras y expresado en número de minutos.

Figura 1. Informativos de las ocho de la tarde. Contenidos en términos porcentuales

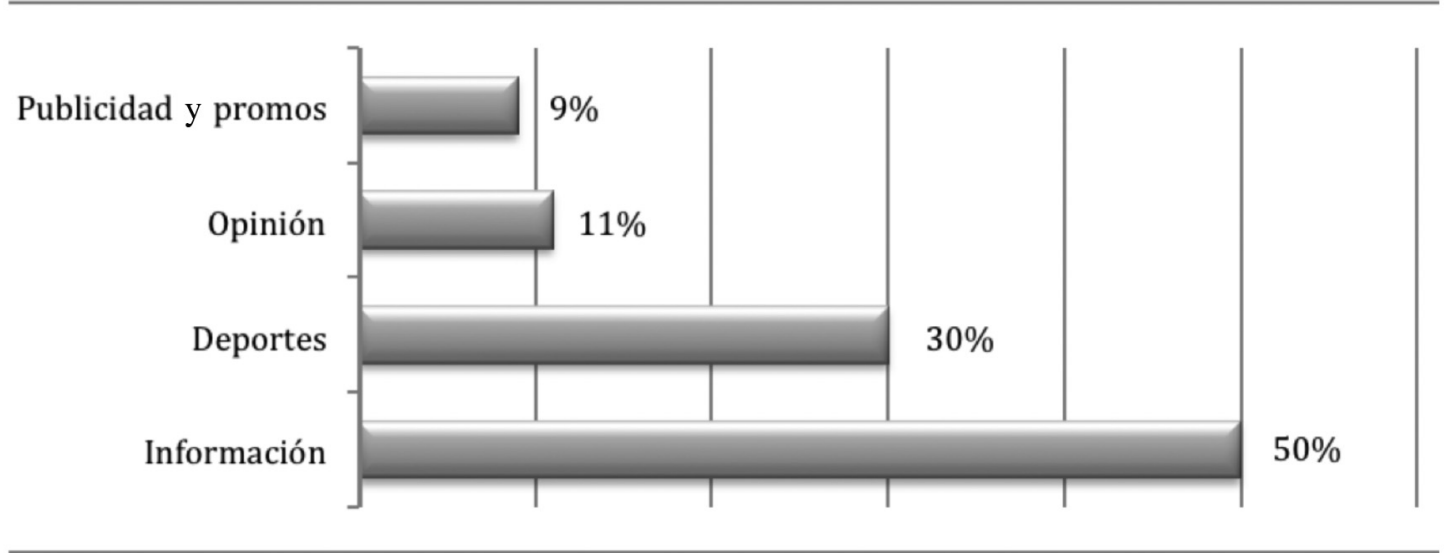


Figura 2. Informativos de las ocho de la tarde. Comparativa Información / Opinión en minutos

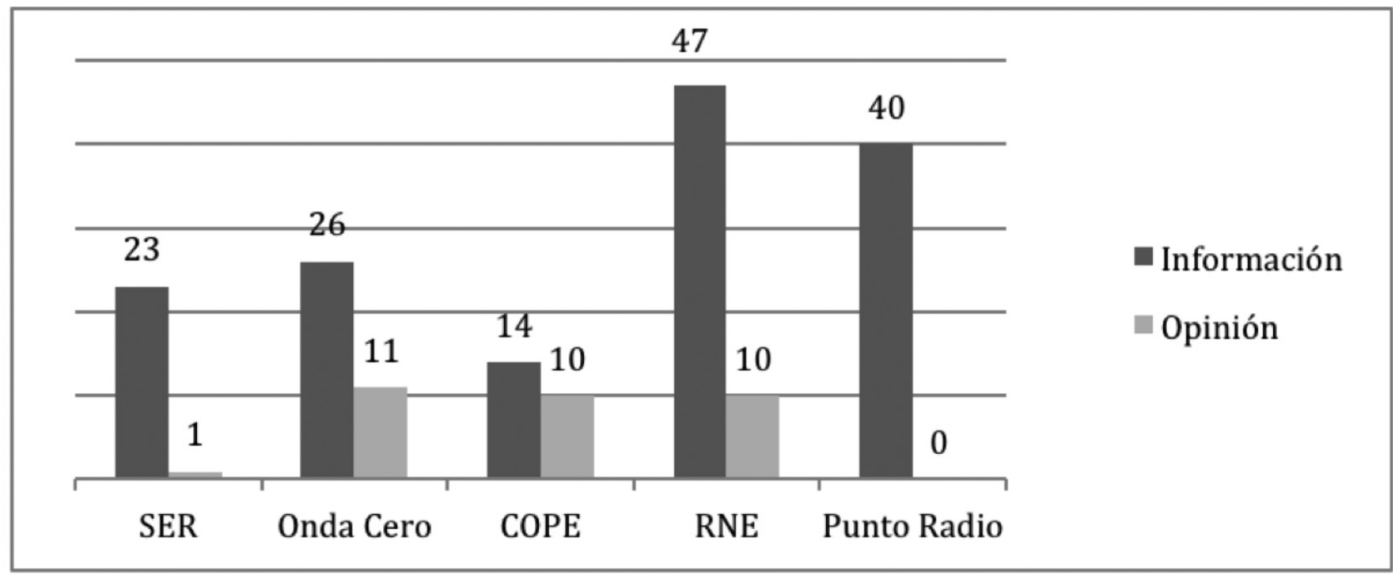

A continuación se separa el apartado de opinión, cadena por cadena, mostrando en primer lugar el número de minutos dedicados al análisis y opinión de noticias (Tabla IV). Acto seguido, se refleja en porcentaje la relevancia que se otorga a la opinión en el total del informativo (Tabla V). Se establecen así hasta cuatro tipologías, dependiendo de la identidad de la fuente emisora, según se trate de expertos externos a los que se recurre en busca de una opinión fundada, de periodistas de prestigio ajenos a la redacción, de oyentes, o del propio presentador.

Tabla IV. Informativos de las ocho de la tarde. Elementos de opinión en número de minutos desglosados por actores

\begin{tabular}{|c|c|c|c|c|c|c|}
\hline & & SER & Onda Cero & COPE & $R N E$ & Punto Radio \\
\hline 1 & Presentador & 0 & 7 & 10 & 0 & 0 \\
\hline 2 & Expertos externos & 0 & 0 & 0 & 10 & 0 \\
\hline 3 & Periodistas ajenos & 0 & 1 & 0 & 0 & 0 \\
\hline \multirow[t]{2}{*}{4} & Oyentes-internautas & 1 & 3 & 0 & 0 & 0 \\
\hline & Total minutos & 1 & 11 & 10 & 10 & 0 \\
\hline
\end{tabular}


Tabla V. Informativos de las ocho de la tarde. Elementos de opinión en \% desglosados por actores

\begin{tabular}{|l|l|l|l|l|l|l|}
\hline & & SER & Onda Cero & COPE & RNE & Punto Radio \\
\hline 1 & Presentador & $0 \%$ & $11,7 \%$ & $17 \%$ & $0 \%$ & $0 \%$ \\
\hline 2 & Expertos externos & $0 \%$ & $0 \%$ & $0 \%$ & $17 \%$ & $0 \%$ \\
\hline 3 & Periodistas ajenos & $0 \%$ & $1,7 \%$ & $0 \%$ & $0 \%$ & $0 \%$ \\
\hline 4 & Oyentes-internautas & $1,7 \%$ & $5 \%$ & $0 \%$ & $0 \%$ & $0 \%$ \\
\hline & Total $\%$ & $1,7 \%$ & $18 \%$ & $17 \%$ & $17 \%$ & $0 \%$ \\
\hline
\end{tabular}

\section{Discusión y conclusiones}

Del estudio realizado se infiere que los informativos de radio, limitados tradicionalmente a la difusión exclusiva de noticias, han evolucionado mayoritariamente hacia modelos "híbridos" que admiten en su seno diferentes manifestaciones de opinión, superándose así la clásica separación de géneros interpretativos y de información.

De este principio general se apartan las emisoras públicas, sometidas a una legislación específica.

Destaca como apuesta firme de los programadores el diario "de autor", en el que se expresa de forma explícita la opinión del presentador en la portada del informativo y en cada una de las entradillas correspondientes a las noticias que se desarrollan.

Aún más generalizada resulta la incorporación de "firmas" de conocidos analistas políticos, mayoritariamente periodistas. Estas colaboraciones aparecen también en aquellos informativos que no ofrecen opinión expresa de su director, en ocasiones, con el propósito de remarcar, justamente, la línea de separación entre la mera transmisión de noticias, que correspondería al presentador, y la interpretación que puedan hacer terceras personas, ajenas a la redacción.

Por último, se aprecia la experimentación que llevan a efecto algunas emisoras, al dar cuenta en sus informativos de las comunicaciones de los oyentes. De entre todos los noticiarios estudiados, los de Onda Cero-seguidos a considerable distancia por los de la Cadena SER- se sitúan a la vanguardia de este proceso de revisión de los informativos de radio, cuyo último hito es la incorporación a la antena de la opinión de distintos actores, y muy singularmente, la que hacen llegar los oyentes a través del correo electrónico y de las redes sociales. 


\section{Referencias bibliográficas}

Anderson, J. A. (1996): Communication theory: epistemological foundations. New York: The Guilford Press.

Armentia, J. I. y Caminos, J. Ma (2009): Redacción informativa en prensa. Barcelona: Ariel.

Blanco, M. (2006): “El impacto de la radio en la vanguardia española: Revista Ondas (1925-1936)”, en Hernández, J. A., García, C., Morales, I. y Coca, F. (eds.): Retórica, literatura y periodismo. Actas del V Seminario Emilio Castelar. Cádiz: Ayto. de Cádiz.

Cloutier, J. (1973): La communication audio-scripto-visuelle à 'heure des self-media, ou l'êre d'Emerec. Montreal: Presses de l’Université de Montreal.

Faus, Á. (2007): La radio en España (1896-1977). Madrid: Taurus.

Gallego Pérez, J. I. (2010): Podcasting. Nuevos modelos de distribución y negocio para los contenidos sonoros. Barcelona: VOCpress Comunicación \# 17.

Garaitaonaindía, C. (1985): “La radiodifusión durante la Dictadura de Primo de Rivera. Los orígenes”, en García, J. L: La crisis de la Restauración en España, entre la Primera Guerra mundial y la II República. II Coloquio de Segovia sobre Historia Contemporánea de España, dirigido por Manuel Tuñón de Lara. Madrid: Siglo XXI.

Garitaonandía, C. (1988): La radio en España (1923-1939): de altavoz musical a arma de propaganda. Bilbao: Universidad del País Vasco.

González, J. (2001): Comunicación radiofónica. De la radio a la universidad. Madrid: Universitas.

Hill, G. (1987): Los informativos en radiotelevisión. Madrid: IORTV.

Instituto de la Opinión Pública (1964): Estudio sobre los medios de comunicación de masas en España, pp. 687-688.

Jaramillo, E.P. (2003): “Desafíos de la radio para el nuevo milenio”, Encuentros, vol. 8. Quito (Ecuador): CIESPAL.

Hendy, D. (2000): Radio in the global age. Cambridge: Polity Press.

Herrera, S. (2005): “Ventajas e inconvenientes de la participación de la audiencia en los programas de radio”, DOXA Comunicación, nº 3, pp. 123-142.

Jenkins, H. (2008): Convergence Culture. Barcelona: Paidós.

Lara, T. (2004): “La nueva esfera pública. Los medios de comunicación como redes sociales”, Telos, n. 76, pp. 128-131.

Lin, Carolyn A. (2001): "Audience attributes, media supplementation and likely online service adoption”, Mass Communication and Society, vol. 4 (1), pp. 19-38.

Livingstone, S. (1999): “New media, new audiences?”, New Media and Society, vol. 1 (1), pp. 59-66.

Manovich, L. (2005): El lenguaje de los nuevos medios de comunicación: La imagen en la era digital. Barcelona: Paidós. 
Martini, S. (2000): Periodismo, noticia y noticiabilidad. Colombia: Norma.

Martini, S. y Luchessi, L. (2004): Los que hacen la noticia. Periodismo, información y poder. Buenos Aires: Biblos.

Miller, K. (2005): Communication theories: perspectives, processes, and contexts. New York: McGraw-Hill.

Muñoz, J. J. y Gil, C. (1994, 2ª ed.): La radio: teoría y práctica. Madrid: IORTV.

Noelle-Neumann, E. (1974): “The spiral of silence: a theory of public opinion”, Journal of Communication, n. 24, pp. 43-51.

Oriol, P. (comp.) (2008): ¿Cómo ganar unas elecciones? Comunicación y movilización en las campañas electorales. Barcelona: Paidós.

Orozco, J. (2009): Radio Nacional de España: nacida para ganar una guerra. Madrid: Manuscritos.

Ortiz, M. A. y Marchamalo, J. (1994): Técnicas de comunicación en radio. Barcelona: Paidós.

Ortiz, M. A. y Volpini, F. (1995): Diseño de programas en radio: guiones, géneros y fórmulas: Paidós.

Ortiz, M. A. (2009): “La creatividad como valor añadido en los contenidos informativos”, Creatividad y Sociedad, nº 13.

Peña, P. (2010): “Nuevas formas de participación en Radio”. Actas del II Congreso Internacional de Comunicación 3.0. Salamanca: Universidad de Salamanca. Disponible en: http://campus.usal.es/ comunicacion3punto0/comunicaciones/ 073.pdf

Sallenave, J. P. (2002): La gerencia integral. Bogotá: Norma.

Shirky, C. (2008): Here comes everybody: The power of organizing without organizations. New York: The Penguin Press.

Tapia, J. (1994): Noticias por la radio. Recuerdo y calidad. Barcelona: Marzo 80.

Ulibarri, E. (1994): Idea y vida del reportaje. México: Trillas.

\section{Otros materiales consultados:}

Manual de estilo de Radio Nacional de España (1980). Madrid: RTVE.

Manual de estilo de la Cadena SER (1988). Madrid: Cadena SER.

Guía de estilo de Onda Cero Radio (s/d). Madrid: Onda Cero Radio. 